\title{
Perspectives of authentic assessment and professional practice interventions in teaching and learning
}

\author{
$M$. Royce, $J$. Jariwala, $M$. Petzer, $J$. Turner \\ Liverpool John Moores University, Liverpool, Great Britain
}

\begin{abstract}
Higher Education is seen as having an expanding responsibility to prepare students for employment. Many of the subject areas taught are linked with particular professions, such as in law, business, engineering and health, and academics may have experience working in the profession before teaching. Professional bodies have input into the curriculum and assessment design, and academic research supports the developing of practice in all areas. This paper draws together and reviews some of the practice and theoretical perspectives of this merging of worlds. The practice elements of the paper reflect work embedded in module development in Liverpool John Moores University in the North West of England. The focus will be situated in the area of authentic assessment and its role within professional practice. The paper will first explore the meaning of professional practice, then use activity theory, in particular boundary crossing, as a framework for a discussion of practice implications.
\end{abstract}

\section{Introduction}

The idea of professional practice can be defined and explored in a number of ways. Segon (2014, p.14) takes us back to Flexner 1910 description of the attributes of professional practice:

1.Possess and draw upon a store of knowledge that was more ordinary than complex

2. Secure a theoretical grasp of the phenomenon with which it dealt

3. Apply its theoretical and complex knowledge to the practical solution of human and social problems

4. Strive to add and improve its stock of knowledge

5. Pass on what it knew to novice generations not in a haphazard fashion but deliberately and formally

6. Establish criteria of admission, legitimate practice and proper conduct and

7. Be imbued with altruistic spirit

There is a lot here to unpack, the altruism, the support for the novice, the admission process and the adding the collective understanding. But can it be said that these are still the underlying values since they were defined 110 years ago? What was once seen as quite a static notion of professional practice of skills and knowledge applied to a relatively stable 
environment has been disrupted by the increase of technological, economic and social change (Kemmis, 2019; Lester, 1995).

\section{Professional practice}

In periods of rapid change, decisions on how we teach and the content of that teaching become more complex ? For Lester (1995), there is a central educational dichotomy of to this question; atomistic visions of key skills or grander theories, between a 'technical rational' model of logical solution finding and a 'post-industrial' acknowledgment of complexity. Lester (1995) argues that this requires professionals to become far more reflective, to embody principles, ethics and morals, it also moves the ownership of description of the practice away from the central body towards the practitioner themselves. Within this paper we will be exploring practice within the Human Resource Management profession and considering the impact of working with the professional body, the Chartered Institute for Personnel and Development (CIPD).

The assessment of competence that delineates the professional from others presents interesting challenges to the more traditional assessment strategies found in Higher Education. Lester (1995) would view application of reflection as an ongoing process as part of the assessment process. The questioning self-action provides a critical connection of theory and practice. Illustrating this, the CIPD advocates the importance of analytics. The ability to understand and interpret human resource (HR) metrics to guide policymaking and people practice is a growing essential requirement for HR practitioners, (CIPD, 2017). The appreciation of metrics enhances problem solving and decision-making faculties associated with demonstrating business acumen, (CIPD, 2018). This narrative lends itself to integrating professional practice to the Higher Education curriculum to prepare students for employment.

Teaching the components of individual key metrics, i.e., staff turnover and sickness absence rate, integrates into the curriculum, in theory but the practice dimension has been largely absent until recently. To resolve this deficiency, a database that would simulate a typical HR staff database was developed by students as part of an extra curriculum project. This database would serve many functions including the appreciation of what and how personal data is organised in workplaces, and the multiple uses not limited to sourcing, establishing patterns, benchmarking, and predicting future people and organisational performance to guide and optimise business sustenance.

Cole et al (2011) explores the cultural gap between the relatively positivistic professional practice and wider theoretical questioning of the academic world. Through the use of real world co-created data, the students are able to identify for themselves the ethical and organisational dilemmas arising from the creation and interpretation of data. They echo Lester's (1995) model with their call for greater reflexivity or a questioning of assumptions and bias within the professional. Such models of working bring students into the cocreation of the curriculum areas and allow for reflexivity which may challenge both teaching and learning and organisational practice models.

In 2018, George Huh provided the keynote address at LJMU's Teaching and Learning conference where he shared his concept of Teaching High Impact Practices (HIPs). Discussion and reflection following this address led academic leaders at LJMU to understand that much of their work in the field of business practice is based on promoting deep learning by promoting student engagement. This has been achieved through curriculum design, assessment and facilitation with content co-created by students. In this example the students choose a job role and identify and measure key competencies related to the job. Collectively, they then design an assessment centre using a range of 
measurements to make a recruitment decision. The students alternatively play the part of assessors and applicants allowing academics to report on both the knowledge and practical application in designing the measurement tasks but also on the way in which the student responds as an applicant. The feedback from both perspectives allows for a rich reflection on knowledge, skills and behaviours and employability readiness. The structure involves students in design influenced by selection theory. The requirement to put their designs into practice increases the performance expectation, encourages students to earn higher grades and retain, integrate, and transfer information at higher rates. There is potential for professional practice learning and assessment similar to this case example to build on the individuality of student knowledge and experience and accelerate the development of peer and independent learning. The student view of practice based learning was captured in a paper to the LJMU Teaching and Learning Conference in 2019 'Student Partners in Designing Professional Content and assessment'. Students reflected on how a blend of HIP based 'modules' within a programme enhanced student independence and accelerated the acquisition of skills more usually only learned from employment rather than an academic environment.

To summarise, professional practice is a contested area. Involvement of students in cocreating materials and operating with real world models one where new skills, such as reflection and reflexivity are being promoted alongside theoretical perspectives. In the next section, we will look at authentic assessment and how it might help embed, develop and support these practices?

\section{Authentic assessment}

Authentic assessment is a summative assessment where the student has a task that mimics a real world task rather than a traditional assessment such as essay or exam. In Villarroel et al's (2018) review of authentic assessment, thirteen consistent characteristics are identified classified into three conceptual dimensions: realism, cognitive challenge and evaluative judgement. Realism relates to the level by which the assessment mimics problems or activities found in practice and replicating the performance standards expected. Cognitive challenges refer to the high order thinking skills such as creativity, problem-solving, and decision-making. Evaluative judgement means how the student should be involved in creating the criteria by which the performance is judged and be more aware of this in order to self-regulate and improve their behaviour such as through self- assessment and reflection. Authentic assessment can be seen as a challenge to traditional assessment practices within education, which fail to provide methods for students to practice their developing skills and knowledge, with some of the drivers for this assessment comes from external professional and regulatory bodies. A move, which in itself can be seen as a challenge to the professionalism of academic practice, as external bodies take more control. However, we could view authentic assessment as a dialogue or exchange around values and skills within professional practice. The case study example illustrating this can be seen through a CIPD accredited module for final year undergraduate students on the BA HRM programme. The module, named Strategic HR Competencies comprises of a combination of lectures and facilitated role plays where students perform roles leading to the undertaking of a mock Employment Tribunal (ET). In the UK these tribunals hear cases relating to breaches of contract and/or Employment Law. During 2020, single employment tribunals and caseloads increased by $13 \%$ and $22 \%$ respectively compared to a year ago with 19000 multiple claims receive in the quarter during July to September 2000. (Gov.uk, 2020). With this significant number of cases, we cannot ignore the importance of this aspect of an HR practitioner's role. Elements of preparation and final tribunal have previously been "live" but due to COVID restrictions in 2020 the role plays were moved into a filmed environment 
using a mix of technologies including Panopto and Zoom. Due consideration is given to individual student levels of confidence and as a result, all tribunal roles are adopted on a voluntary basis. In taking responsibility for differing roles in the case study, students learn to work collaboratively with each other but also independently of direct academic direction. Students make choices about their approach to the problems presented and the consequences of the decisions they make and are assessed on five reflective elements.

The students shape the curriculum. Four fictitious groups; Organisational HR Department; aggrieved individuals seeking redress for a breach; the line managers involved in the decisions which have led to the claim for a breach of policy or employment law and the ET panel members. Each group receives a set of initial notes which differ and reflect their own perspective and version of truth. The groups do not share this information. The practice based role play is supported by knowledge creating short lectures on the legal, policy and theory context relevant to the case. The students then build a role play and respond to information as it emerges from the other groups and the academic leader of the module. The module concludes with a mock trial, which is recorded so that students can use this to reflect on their levels of knowledge, preparation and decision making. The ET panel members collectively decide on a suitable outcome of the case and calculate an award based on legal knowledge gained through lectures. The assessment is reflexive, relates to the work of Cole et al. (2011) evaluation and critique in the following areas: HR competencies in managing conflict; good practice in investigations; justification of organisational and individual actions; preparation for and delivery of tribunal role play and documentation; reflection on organisational process improvement. Student feedback in this practice based module is strong with students reflecting on the extent to which the ability to work with real time changing scenarios helped prepare them for work in their chosen profession.

The evaluation process for professional practice academic delivery and assessment must respond to flexibility in the choices made by the students during the course of the module and student involvement in understanding the multiple layers of complexity inevitably requires academic time and resources. While the students are independent learners for much of the assessment the curation and facilitation of the academic lead requires both professional practice knowledge and skill in integrating the two worlds of academic rigour and clinical business practice.

\section{Professional Body Relationship}

The CIPD skills and behavioural framework for practitioners is embedded into the academic delivery of modules within an accredited programme such as the BA (Hons) Human Resource Management used in the case examples within this paper. CIPD have emphasised the demonstration of business acumen in HR practitioners and recognises (CIPD, 2018) the importance of integrating professional practice into the Higher Education curriculum to prepare students for employment. The close working relationship between the professional body, CIPD and the academic subject leaders created a partnership with the students evident in the development of materials, delivery and assessment of practitioner work involving data base analysis, assessment of competencies for recruitment and the investigation and decision making involved in the tribunal.

\section{Conclusions}

Defining professional practice: The defining of the skills, knowledge, values and behaviours are a crossing point. This article has shown a number of different visions from 
the academic literature and has provided practice examples but there is more work to be undertaken in developing academic practice informed by professional bodies discourse and definitions. The Business School in LJMU are learning to provide shared spaces where academic theoretical concepts and business practice are explored together. In a world of rapid change it becomes important that this shared space expands and that developmental work is not considered in isolation.

Shared conceptual language and discourse: The descriptions of professional practice will differ depending on which community is discussing it. A three way partnership between professional body, academics and students will allow space to develop a shared understanding to help define practice. This development in language be beneficial in itself.

Authentic assessment: The development of authentic assessments requires the partners to begin to walk in each other's shoes. How can the development and refinement of this help to define the roles each party takes and the objectives each has?

The student: The students are a shared locus of control, between the professional bodies and academics, but the student also needs to validate their own agency in the space in order to develop their skills, knowledge and begin to embody that practice. The student is the focus, but they are active participants in this process too. They additionally provide the opportunity for both parties to benefit from their reflections. For this to happen, the student needs to be empowered with their own skills and knowledge to complete this extra task.

Boundary crossing and professional practice: Flexner's 1910 attributes of professional practice described at the beginning of this paper, do not explicitly reference an ability to work laterally across fields as well as vertically with a field of expertise. As fields of practice have multiplied and crossed over, the points where they have crossed over have increased. The next generation of professionals will no doubt work in more diverse teams. They will need to work and develop relationships in the virtual as well as the physical world and the need for shared community understanding of practice and behaviours will be even more evident than it is today. Their ability to boundary cross will increasingly become an important skill within their practice. How do we design authentic assessments to support the development of those skills? In addition to this, academics and professionals need to develop these skills in order to improve the process if all parties are to learn from the process.

Evidence of impact from student perspective:

'During this module I've learnt that often employees are reluctant to raise a grievance in the workplace due to fears of retribution from management or becoming the center of workplace gossip. Having learned this, I feel it would be important to form good working relationships quickly with colleagues and have the ability to empathize with them and support them through the whole process.' Student A.

'During this module, I had the opportunity to assess a role play, including a grievance, disciplinary and employment tribunal. I felt emotionally involved with the case and as mentioned previously, I had to learn to evaluate my decisions based on facts rather than how I felt which I found difficult to do at first. For me, the most significant part was being able to follow the process through from beginning to end. In my previous experience, I had only experienced some aspects. Therefore, this was useful to better my understanding of each part of the process. Reflecting on this experience, I now realise people may act out and be difficult in situations such as these. Having experienced this, I now feel I would be prepared to deal with a difficult situation where there are hostile behaviours and I feel conflicted between my emotions and professionalism. I feel I have developed my professional resilience and communication skills when talking to emotional individuals. These skills are essential for a HR professional as being able to communicate effectively during difficult situations is crucial.' Student B. 
'During week eight we learnt about the preparation needed for employment tribunals and we looked at the typical compensation awards different grievances can attract. To my surprise, compensation can be awarded in cases where there is an injury to feelings - this includes financial compensation for feelings of humiliation, distress or anxiety. This has intrigued me as it was not something I knew before and I am interested to learn more about this - particularly looking at how you would measure or quantify the 'injury' and justify the financial compensation.' Student C.

\section{References}

1. CIPD New Professional Map [online] available at https://peopleprofession.cipd.org/profession-map (2018)

2. CIPD New CIPD research calls for professionals to use HR analytics to improve evidence-based practice [online] https://www.cipd.co.uk/news-views/news-articles/hranalytics-reserach [Accessed 17th December 2020] (2017)

3. C. Cole, S. Chase, O. Couch, M. Clark, Research Methodologies and Professional Practice: Considerations and Practicalities, Electronic Journal of Business Research Methods, Academic Conferences International Limited, 9. 2. 141 (2011)

4. Y. Engeström, R. Engeström, M. Kärkkäinen, Polycontextuality and boundary crossing in expert cognition: Learning and problem solving in complex work activities, Learning and Instruction, Pergamon, 5. 4. 319 (1995)

5. https://www.gov.uk/government/publications/tribunal-statistics-quarterly-july-toseptember-2020/tribunal-statistics-quarterly-july-to-september-2020

6. N.A. Jankowski, J.D. Timmer, J. Kinzie, G.D. Kuh, National Institute for Learning Outcomes Assessment 2. National Institute for Learning Outcomes Assessment, (2018)

7. S. Kemmis, Understanding Professional Practice. A Synoptic Framework, Understanding and Researching Professional Practice, 19 (2019)

8. G.D. Kuh, S.O. Ikenberry, N.A. Jankowski, T.R. Cain, P.T. Ewell, Hutchings, P. J. Kinzie, Beyond Compliance: Making Assessment Matter, The Magazine of Higher Learning, Informa UK Limited, 47. 5. 8. (2015)

9. G.D Kuh High Impact Educational Practices: A Brief Overview. Available at www.AACU.org (2008)

10. S. Lester, Beyond Knowledge and Competence towards a Framework for Professional Education, Capability, 1. (1995)

11. M. Segon, Managing Organisational Ethics: Professionalism, Duty and HR Practitioners. Journal of Law and Governance, Victoria University, 5. 4. available at:https://doi.org/10.15209/jbsge.v5i4.191. (2014)

12. D. Soehren, Student Partners in Designing Professional Content and assessment. Paper presented at the 2019 Teaching and Learning Conference, Liverpool John Moores University as part of the Teaching and Learning Academy Enhancement Strategy www.ljmu.ac.uk/academic-registry/teaching-and-learning-academy/enhancement (2019)

13. V. Villarroel, S. Bloxham, D. Bruna, C. Bruna, C. Herrera-Seda, Authentic assessment: creating a blueprint for course design, Assessment and Evaluation in Higher Education, Routledge, 43. 5. 840 (2018) 